\title{
Mesoscale convective systems in Spain: instability conditions and moisture sources involved
}

\author{
S. Queralt ${ }^{1}$, E. Hernandez ${ }^{1}$, D. Gallego ${ }^{2}$, and P. Lorente ${ }^{1}$ \\ ${ }^{1}$ Universidad Complutense de Madrid, Madrid, Spain \\ ${ }^{2}$ Universidad Pablo de Olavide, Sevilla, Spain
}

Received: 1 August 2007 - Revised: 17 December 2007 - Accepted: 18 February 2008 - Published: 9 April 2008

\begin{abstract}
Source-receptor water vapor content areas are analyzed for a particular case of deep mesoscale convective system (MCS) developed over the Mediterranean margin of Spain in October 1982. The aim of this work is to study simultaneously the atmospheric instability conditions and water vapour fluxes which finally resulted in very severe precipitation rates, reaching up to $600 \mathrm{~mm}$ in a single day. Humidity amounts and transport are quantified along the trajectories computed from a lagrangian particle simulation model (FLEXPART6.2). To evaluate the precipitation probability, the water vapor content and both thermodynamic and dynamic atmospheric instability components were assessed. The October 1982 Iberian MCS occurred as a consequence of a deep cutoff low detected between 500 and $200 \mathrm{hPa}$ levels. The dynamical instability was measured through potential vorticity anomalies and $\mathrm{Q}$ vector divergence, which presented their maximum and minimum centers respectively over south-eastern Iberia. Synoptic and dynamic instability conditions were obtained from the ERA40 reanalysis dataset. It is observed that during this severe weather episode, the specific humidity increased along the lowest and easternmost trajectories, which are mainly spread over the Mediterranean Sea.
\end{abstract}

\section{Introduction}

Severe convection events are especially intense over the west Mediterranean Sea basin. In particular, eastern Spain is characterized by frequent events of torrential rainfalls. Historically, special interest has been focused on understanding the Mesoscale Convective Systems (MCSs) due to the important damages and fatalities involved in these episodes.

Correspondence to: S. Queralt

(queralt@fis.ucm.es)
Several Iberian MCSs case studies have been largely described (Romero et al., 2000) revealing that convective environment was mainly the result of low level advection of warm and moist air from the Mediterranean Sea to the Spanish coast. Recently, Garcia-Herrera et al. (2005) developed a general MSCs climatology. They found that moisture charging is specially intense during the fall season. However, the available humidity content was difficult to determine.

A strong MCS was developed during October 1982 over eastern Spain and it was especially strengthened over the city of Tous (Fig. 1). After three days of heavy rainfall, Jucar river overflowed and Tous dam collapsed on 20 October 1982. The flood caused important damages and casualties. The objective of this paper is to characterize the instability conditions and synoptic context leading to this MCS by using a lagrangian particle simulation model (Stohl et al., 2004, 2005).

In the following section, the dataset used in this study is presented. In the third section, some synoptic features of the MSC are described, instability indices are evaluated and a backward trajectory characterization is performed. Fourth section summarises the most relevant conclusions.

\section{Data set and methodology}

Several databases have been used in this study:

\subsection{Radiosondes}

Daily radiosondes (00:00 and 12:00 UTC) from the Integrated Global Radiosonde Archive have been used. Radiosoundings from Palma de Mallorca station (Fig. 1) have been evaluated in order to determine thermodynamic instability indices from 18 to 23 October. Instability data were compared with daily rainfall observations. CAPE, LI, TT, $\mathrm{KI}$, SI and SWEAT are analyzed in order to characterize the thermodynamic instability.

Published by Copernicus Publications on behalf of the European Geosciences Union. 


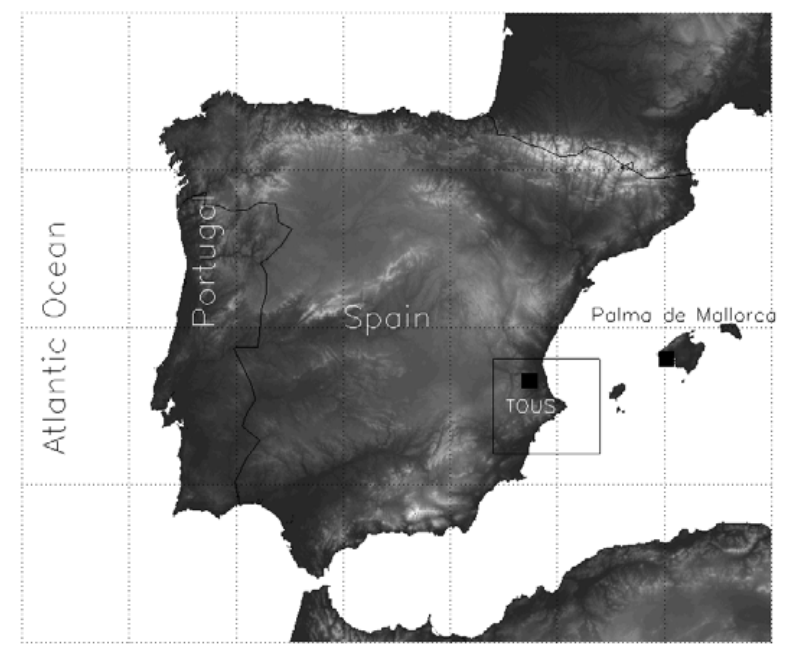

Fig. 1. Iberian Peninsula; Tous location inside the box.

\subsection{ERA-40 Reanalysis}

The synoptic situations and dynamic instability have been characterized by using the ERA-40 reanalysis (horizontal and vertical velocity components, temperature and geopotential height) over an area extending from $15^{\circ} \mathrm{N}$ to $70^{\circ} \mathrm{N}$ and $25^{\circ} \mathrm{W}$ to $25^{\circ} \mathrm{E}$, with $0.5^{\circ} \times 0.5^{\circ}$ spatial resolution. Dynamic instability has been evaluated through Potential Vorticity (PV) anomalies and Q vector divergence (dQ). PV anomalies were obtained substracting the monthly mean value. PV anomalies at $330 \mathrm{~K}$ isentropic surface were performed. PV cross sections (between 850 and $100 \mathrm{hPa}$ ) were also analyzed in order to evaluate the foldings of the dynamical tropopause (DT), defined by the usual threshold of 2 Potential Vorticity Units (PVU) (Hoskins et al., 1985), (1 $\mathrm{PVU}=10^{-6} \mathrm{Km}^{2} \mathrm{~s}^{-1} \mathrm{~kg}^{-1}$ ) and the potential exchanges between the stratosphere (S) and the troposphere (T). It is well known that most of the characteristics of a MCS as cut-off lows, tropopause foldings and thunderstorms have been identified as dynamical structures associated with StratosphereTroposphere exchange (Sprenger, 2007).

Both dQ at $850 \mathrm{hPa}(\mathrm{dQ} 850)$ and $500 \mathrm{hPa}(\mathrm{dQ} 500)(\mathrm{kPa}$ $\mathrm{m}^{-2} \mathrm{~s}^{-1}$ ) at 00:00 UTC and 12:00 UTC have been computed as follows (Hoskins et al., 1978):

$$
\left(\nabla^{2}+\frac{f^{2}}{\sigma} \frac{\partial^{2}}{\partial p^{2}}\right) \omega=-\frac{2}{\sigma} \nabla \cdot \boldsymbol{Q}
$$

where, $f$ is the Coriolis parameter, $\omega(x, y, p, t)$ is the vertical velocity and $\sigma$ is the stability parameter.

Reanalysis data were also used to characterize the location of the jet stream following the method developed by Gallego et al. (2005) which is based on the geostrophic wind at 200 $\mathrm{hPa}$.
Table 1. The ten classes of CWTs (Trigo et al., 2000) and associated humidity transport in Iberia.

\begin{tabular}{lll}
\hline CWTs & Symbol & Associated flux in Iberia \\
\hline Anticyclonic type & A & Variable \\
\hline Cyclonic type & C & Wet \\
Northeasterly type & NE & Dry \\
Easterly type & E & Dry \\
Southeasterly type & SE & Dry \\
Southerly type & S & Dry \\
Southwesterly type & SW & Wet \\
Westerly type & W & Wet \\
Northwesterly type & NW & Variable \\
Northerly type & N & Variable \\
\hline
\end{tabular}

\subsection{Back-trajectories from the FLEXPART model}

The model FLEXPART6.2 (James et al., 2004; Stohl et al., 2004,2005 ) was run in order to examine the available humidity sources of the air masses involved in the Iberian MCS episode. One million particles were launched by the dispersion model in backward mode. Back-trajectories and moisture content evolution were computed in 3-h steps.

\subsection{Atmospheric circulation weather types}

Atmospheric circulation patterns involved in the Tous MCS study case were evaluated with the Circulation Weather Types (CWTs) classification scheme developed by Trigo et al. (2000) and Paredes et al. (2006) for the Iberian Peninsula. These patterns give a first insight about the dominant atmospheric flow regime and the expected moisture transport.

\section{Results}

\subsection{Synoptic environmental features}

\subsubsection{Low level}

The Iberian CWTs are characterized by a set of indices associated with the direction and vorticy of geostrophic flow. They are based on the composites of the sea level pressure (Trigo et al., 2000). This daily circulation scheme allows to define ten different types of patterns with a characteristic SLP field and to approach the humidity content fluxes (Table 1) for the Iberian Peninsula. As it is shown in Table 2, the central days of Tous MCS development (19 to 21 October) are characterized by a transition from Anticyclonic to Cyclonic regime.

Geopotential height at $1000 \mathrm{hPa}$ (not shown) has also been evaluated in order to verify the CWTs and to examine the low level structures present during the Tous MCS. 

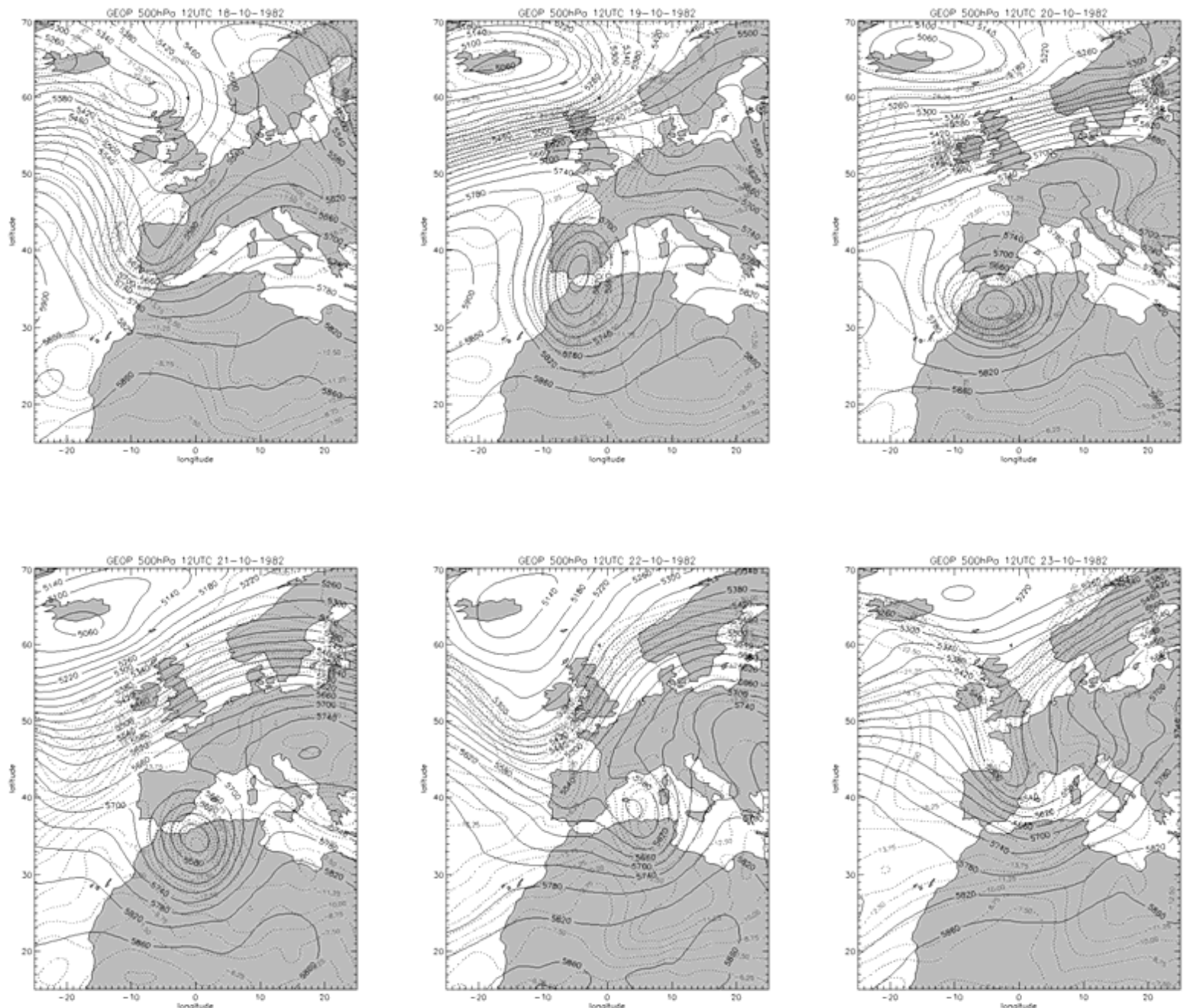

Fig. 2. Geopotential height at $500 \mathrm{hPa}$ (solid lines) and temperature (dotted lines) for 18 to 23 October 1982.

\subsubsection{Middle-High levels}

The October 1982 Iberian MCS occurred jointly with a 4day persistent cut-off low detected at mid-upper levels (between 500-200 hPa), and identified from an objective algorithm (Nieto et al., 2005). As it is shown in Fig. 2, temperature in the cut-off center was lower than $-22^{\circ} \mathrm{C}$.

Geopotential heights at $200 \mathrm{hPa}$ (not shown) have also been analyzed to assess the upper troposphere. Between 18 and 23 October, the geopotential configuration at both $500 \mathrm{hPa}$ and $200 \mathrm{hPa}$ levels was essentially the same. By 18 October, an intense Iberia-centred trough was developing a deep cut-off low in Southern Iberia and Northern Morocco (Fig. 2). This structure persisted during the following four days (19 to 22 October, inclusive) and it was recognized simulaneously at $500 \mathrm{hPa}$ and $200 \mathrm{hPa}$. After 23 October, the cut-off low got dissipated and it was followed by a new trough.
Table 2. CWTs associated with Tous MCS.

\begin{tabular}{ll}
\hline Day/Time & CWTs \\
\hline 18 00:00 UTC & NW \\
18 12:00 UTC & N \\
19 00:00 UTC & A-N \\
$1912: 00$ UTC & A-NE \\
$2000: 00$ UTC & A \\
$2012: 00$ UTC & NE \\
$2100: 00$ UTC & C-N \\
$2112: 00$ UTC & C-N \\
$2200: 00$ UTC & N \\
$2212: 00$ UTC & NW \\
23 00:00 UTC & A-NW \\
$2312: 00$ UTC & A \\
\hline
\end{tabular}



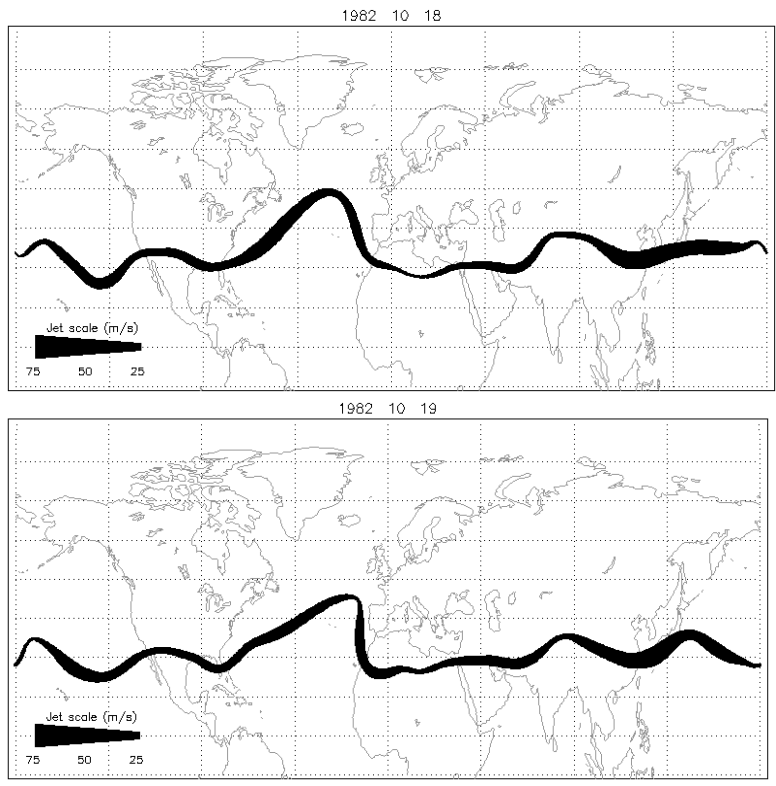

Fig. 3. Jet position for 18 to 21 October 1982.

\subsubsection{Jet stream positions}

Subtropical jet stream is found to be deeply perturbed for 18 and 19 October 1982 close to the Iberian Peninsula, as it is shown in Fig. 3. The subtropical jet tends to be smoother in the following days. The highest perturbation on 19 October is in good agreement with the geopotential field (Fig. 2) and the PV anomalies (Fig. 4). The geopotential field for 19 October shows a cut-off low in rapid development in accordance with the maxima positive PV anomaly (stratospheric air instrusion) (Lamarque et al., 1994).

The Polar jet position is not available until 20 October, since the highest velocity of the geostrophic flow could not properly be defined. Rossby wave propagation could be prevented or broken on the previous days, while from 20 October onwards, the polar jet position is available and seems not to be affecting the MCS.

\section{Dynamic and thermodynamic instability conditions}

\subsection{Thermodynamic instability}

Thermodynamic instability indices were provided by the Palma de Mallorca radiosounding station. Among others, Convective Available Potential Energy (CAPE), Lifted Index (LI), K-Index (KI), Total Totals (TT), Showalter Index (SI) and Severe Weather Threat Index (SWEAT) were analyzed, in order to evaluate the degree of thermal atmospheric instability associated with the Iberian MCS (Table 3). CAPE is in J/kg; LI, TT, KI, SWEAT, and SI are dimensionless. In-
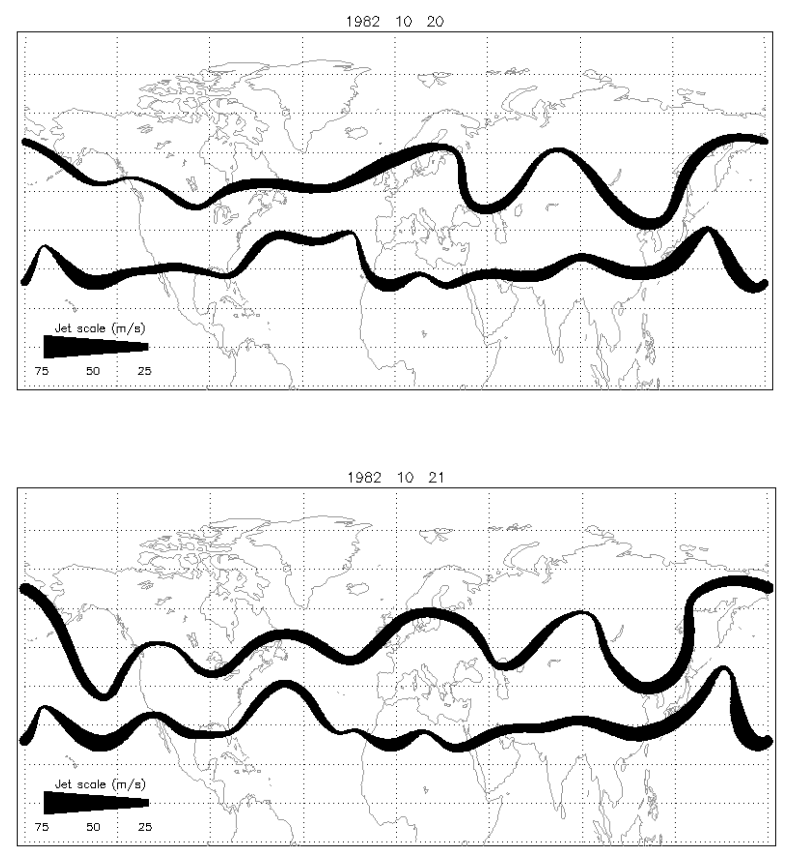

stability thresholds are: CAPE $>1000 \mathrm{~J} / \mathrm{kg}, \mathrm{LI}<0, \mathrm{TT}>44$, $\mathrm{KI}>25$, SWEAT $>200, \mathrm{SI}<4$.

The results showed that the greater part of the thermodynamic indices exceeded its $90 \%$ percentile during the Iberian MCS of October 1982. On 20 October, instability is so excessive that indices cannot be computed.

\subsection{Dynamic instability}

Q vector divergence at 500 and $850 \mathrm{hPa}$ and PV anomaly at $330 \mathrm{~K}$ isentropic surface (Table 3) shows large anomalies over Tous during the heavy rainfall episode. Positive values of dQ (divergence) indicate air mass subsidence, while negative values (convergence) represent upward movements. Maximum convective instability (CAPE and LI, or instance) occurred at 00:00 UTC 21 October and 12:00 UTC 21 October which are also characterized by strong convergence at both levels (negative values for dQ500 and dQ850). At 12:00 UTC 20 October, the highest negative dQ500 value is found, indicating ascending air at the $500 \mathrm{hPa}$ level. This strong rising or air is accompanied by PV negative anomaly, hence the DT movement towards higher levels made the air lifting possible.

Regarding PV, positive anomalies above 2 PVU are considered as stratospheric air intrusions and therefore, an indication of high dynamic instability. The maximum positive $\mathrm{PV}$ anomalies of 19 October are in agreement with the high value of positive dQ at both levels. In addition, $\mathrm{PV}$ anomalies were performed in horizontal fields and vertical cross sections (Fig. 4). On 19 October, a tropopause folding was developed, as DT reached a pressure level lower than $500 \mathrm{hPa}$ 

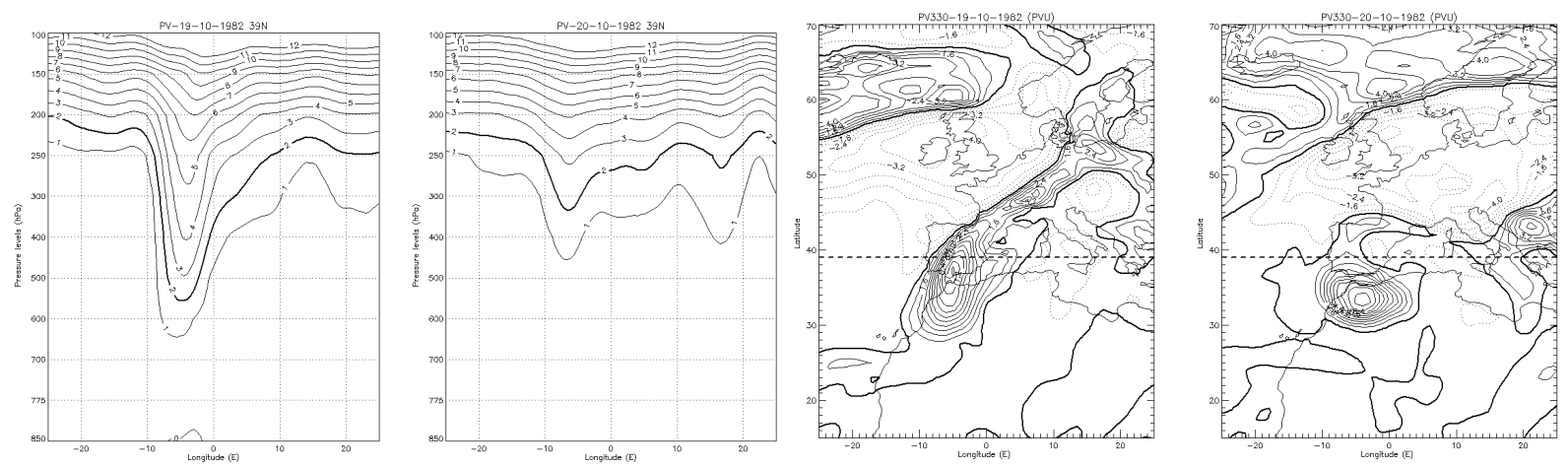

Fig. 4. Top: PV vertical cross section (thick solid line indicates Dynamical Tropopause) at Tous latitude ( $\left.39^{\circ} \mathrm{N}\right)$ for 18 October (left) and 20 October (right), 1982. Bottom: $330 \mathrm{~K}$ isentropic PV anomaly for the same days, thick solid line indicates where PV anomaly is zero, solid lines show positive anomalies and dotted lines show negative anomalies.

Table 3. Thermodynamic and dynamic indices related to Tous MCS. Bold fonts indicate that the instability threshold is exceeded.

\begin{tabular}{llllllllll}
\hline Day/Time & LI & KI & TT & CAPE & SI & SWEAT & dQ850 & dQ500 & PV330 \\
\hline 18 00:00 UTC & -0.7 & 20.9 & 43.6 & 140.2 & 4.5 & - & -5.3 & 0.5 & 1.2 \\
18 12:00 UTC & -0.8 & 34.0 & 46.3 & 118.0 & 0.8 & - & 0.4 & -0.4 & 0.7 \\
19 00:00 UTC & -2.0 & 12.3 & 48.6 & 771.9 & 1.2 & 162.6 & 0.9 & 8.8 & 5.1 \\
19 12:00 UTC & 3.9 & 22.7 & 41.2 & 0.2 & 6.5 & 122.4 & 0.4 & 6.7 & 3.8 \\
20 00:00 UTC & -2.7 & 30.0 & 52.0 & 1243.3 & 1.9 & - & -1.1 & -1.2 & 1.8 \\
20 12:00 UTC & - & - & - & - & - & - & 7.2 & -7.0 & -0.1 \\
21 00:00 UTC & -1.0 & 33.8 & 47.7 & 632.2 & 0.4 & 229.9 & 1.4 & -0.3 & 1.0 \\
21 12:00 UTC & -3.0 & 21.3 & 46.4 & 1383.8 & 1.4 & 215.2 & -7.2 & -0.8 & 1.8 \\
22 00:00 UTC & 4.3 & 25.4 & 40.6 & 7.6 & 6.4 & 123.6 & -3.3 & 2.0 & 0.6 \\
22 12:00 UTC & 0.8 & 16.4 & 46.5 & 29.7 & 4.1 & 107.2 & 3.9 & -1.8 & -0.8 \\
23 00:00 UTC & 3.6 & 25.1 & 42.1 & 0.0 & 4.6 & 125.2 & -6.8 & 5.1 & 3.6 \\
23 12:00 UTC & 3.2 & - & 45.4 & 8.75 & 5.9 & 91.9 & -1.1 & -4.3 & 1.9 \\
\hline
\end{tabular}

over Iberian longitudes $\left(-9^{\circ} \mathrm{W}\right.$ to $\left.0^{\circ} \mathrm{E}\right)$. On 20 October, DT moved into upper levels, and PV anomalies were up to negative values.

Maximum subpolar jet stream perturbations occurred simultaneously to the DT folding. In accordance with the jet stream restoration into non-disturbed state, $\mathrm{PV}$ anomalies recover the usual tropospheric values (underneath $2 \mathrm{PVU}$ ).

\section{Backward trajectories}

The atmospheric particles over eastern Iberia, between 15 and 25 October, with specific humidity (at the moment they arrive in Tous) greater than $0.0075 \mathrm{~kg} / \mathrm{kg}$ were selected to perform 72-h backward trajectories, tracking the moisture changes along the paths (Figs. 5 and 6).

In Figs. 5 and 6 dry (light grey) and wet (dark grey) atmospheric particles arriving in eastern Iberia on 18 October (00:00 and 12:00 UTC) show western paths, slightly turning to northwest trajectory components on 19 and 20 October. Under this atmospheric flux, the intense precipitations start to increase the Jucar river flow (close to Tous). In the course of 20 October, trajectories exhibit a rapid change into southeast and east components, coming from northern Africa and the eastern Mediterranean Sea, respectively. Dry (higher heights) and wet (lower heights) particle trajectories show similar signatures. Dry particles get large amounts of water along their trajectories, due to available humidity sources, even as far as the Nile basin in Northern Africa. Dry particles became wet at the arrival time. The Jucar river flow keeps increasing, reaching dangerous levels.

Dry and wet particle trajectories start to diverge during 21 October. Low-level particles spread over Mediterranean Sea, with a component coupled to the current cyclonic CWT, bringing humidity towards eastern Iberian coast. At higher levels, particles with a nortwest and cyclonic component carry low moisture amounts. Trajectories describe a shearlike vertical profile, where the highest and driest particles show a western component and the lowest and wettest particles exhibit eastern origin. This vertical behaviour implies strong stratiform instability. 

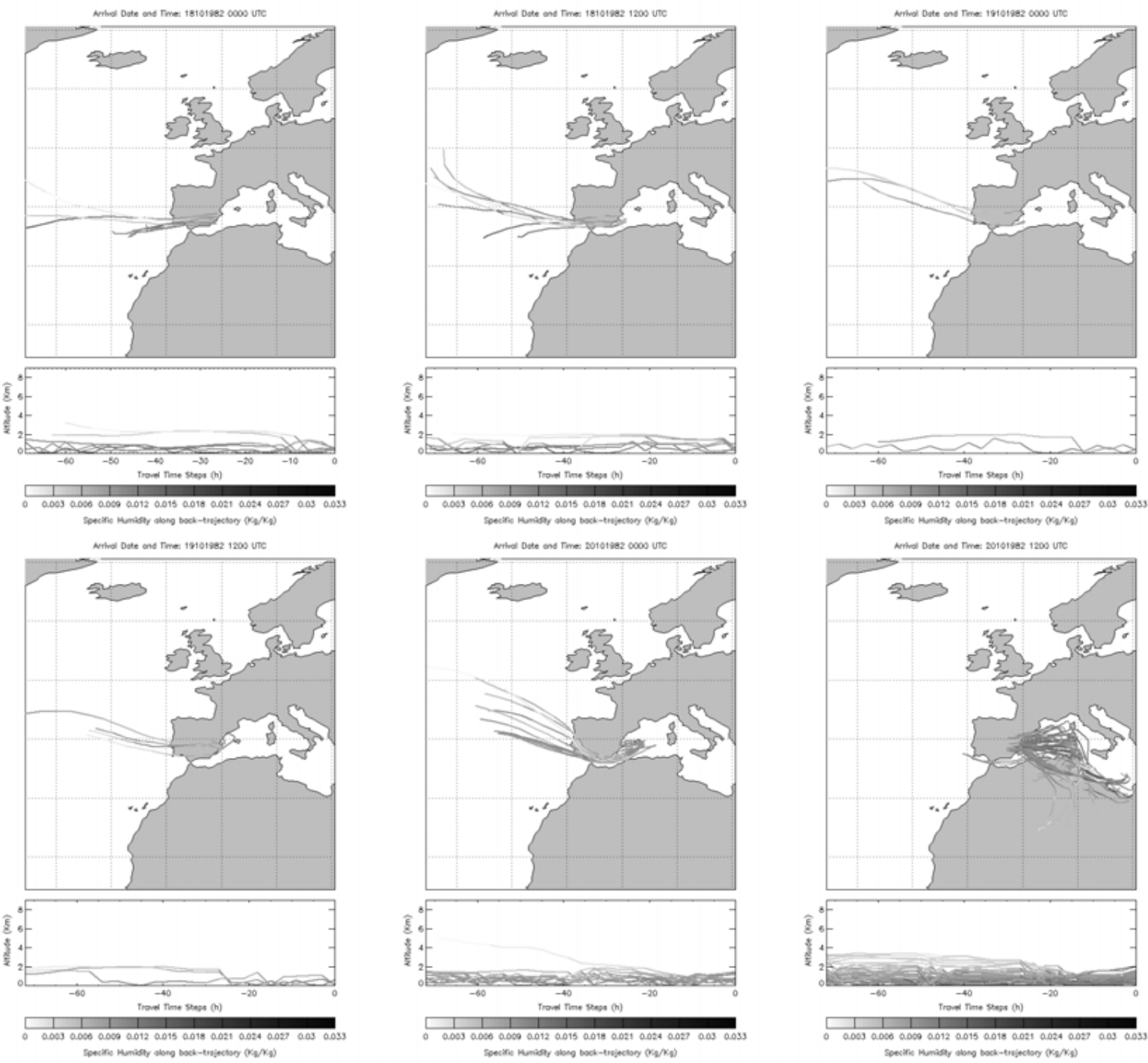

Fig. 5. 72-h backward trajectories of wet (dark grey) and dry (light grey) particles involved in Tous MCS which arrive in eastern Iberia at 00:00 and 12:00 UTC of 18, 19 and 20 October. Specific humidity at the arrival time is higher than $0.0075 \mathrm{~kg} / \mathrm{kg}$.

The persistent rainfall episode causes the Jucar river overflow, and the dam of Tous collapses at 19:15 UTC.

Air particles still transport large amounts of humidity to the eastern Iberia during 22 October. However, moisture content and number of particles involved decrease as the cutoff low starts to disappear. Most of 00:00 UTC 22 October wet trajectories maintain a pure east component, while at 12:00 UTC trajectories show a twisted component at the last part of their paths towards eastern Iberia. On 23 October, the cut-off low was over and only dry particles arrived at eastern Iberia, coming from northwest, thus, restoring the stable conditions.

\section{Conclusions}

Instability conditions and backward trajectories of the $20 \mathrm{Oc}-$ tober 1982 Iberian MCS, were analyzed in order to assess the evolution of the dynamic and thermodynamic structures which led to the intense rainfall episode.

Instability components showed large instable conditions consistent with the synoptic situation and the observed precipitation rates. Middle to upper level unstable structures can be explained by the DT behavior and low level structures are in good agreement with CWTs and wet atmospheric particles paths. The evolution of upper level dynamic structures (jet stream, cut-off low, DT folds) affected the local low level circulation patterns. 

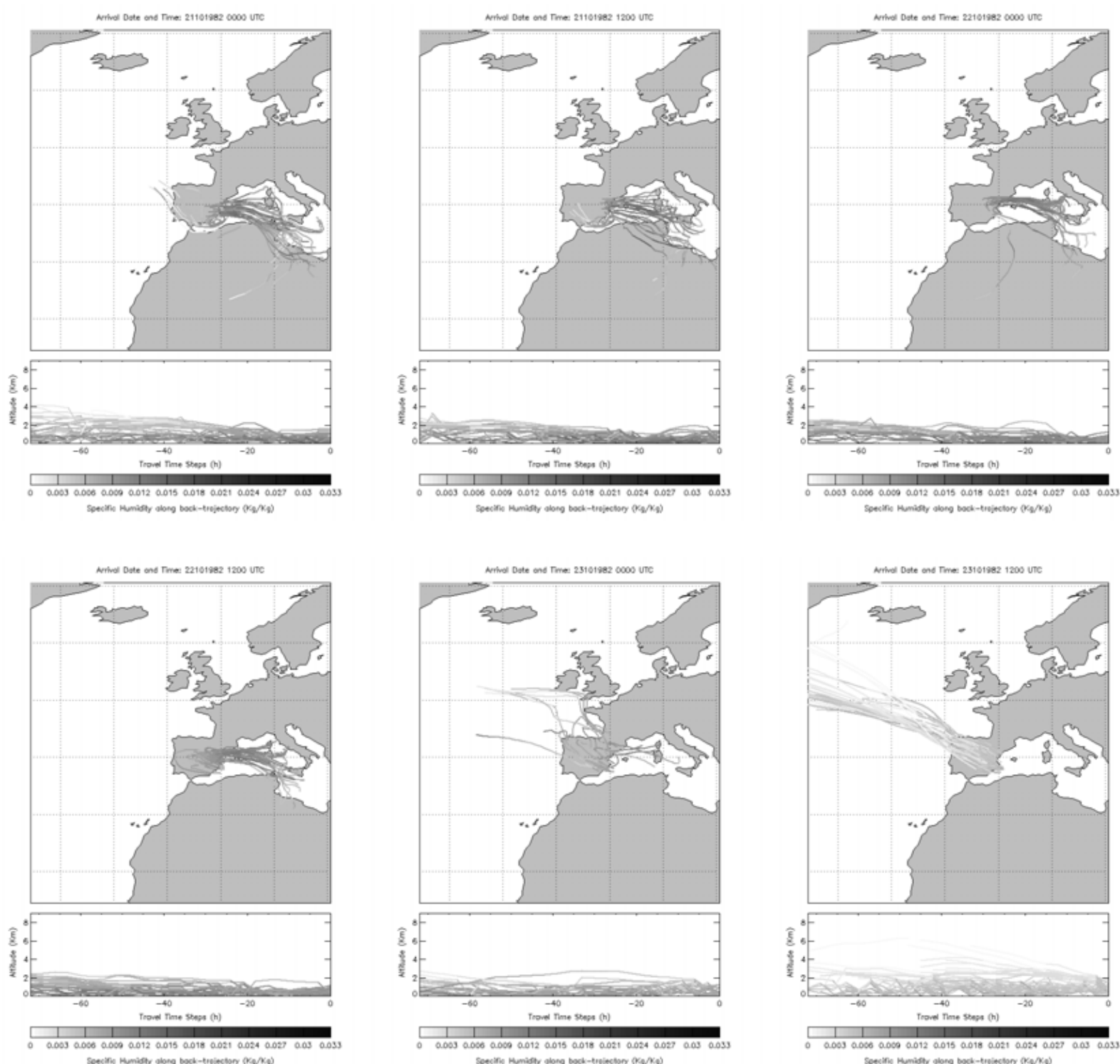

Fig. 6. As in Fig. 5, but for 21, 22 and 23 October.

On 19 October, a DT folding (derived from the upper level cut-off low) was detected as a large PV anomaly over Tous region. These positive PV anomalies occurred together with positive dQ values at both $500 \mathrm{hPa}$ and $850 \mathrm{hPa}$ levels, thus, downward air movements occurred. DT foldings injected stratospheric air into the troposphere, bringing strong thermal instability and anticyclonic circulation at lower levels. On 20 October, DT showed a rebound effect rising higher levels. This DT movement towards higher levels on 20 and 21 October occurred together with dQ negative values, and partially explain the development of the convective system over Tous. Static instability indices on 20 October showed an atmospheric thermal inversion accordingly with the severe convective system development. At lower levels, during
20 and 21 October, CWTs turned to cyclonic circulation. Although the DT bending was still present on 22 October, mass convergence weakened as the cut-off low and the MCS did.

As a consequence of the upper level structures shift, lower levels exhibited a rapid transition from Anticyclonic to $\mathrm{Cy}-$ clonic CWT regimes which led to a shear-like vertical profile. As a result, instability conditions were reinforced as the thermodynamic indices and backward trajectories have shown.

Back-trajectories provide a detailed and new perspective for the analysis of MCSs. The assessment of humidity sources origin and the evaluation of the different air mass trajectories allow a better understanding of hazard rainfall episodes and provide a powerful tool for forecasting and warning against potential damages. 
Acknowledgements. The authors wish to thank U.C.M. and M.E.C for the grant and contract respectively, associated to CG04-05187CO3-01/CLI project. Special thanks to S. C. Michaelides for all the useful comments and helpfulness.

Edited by: S. C. Michaelides

Reviewed by: two anonymous referees

\section{References}

Gallego, D., Ribera, P., García-Herrera, R., Hernández, E., and Gimeno, L.: A new look for the Southern Hemisphere jet stream, Clim. Dynam., 24, 607-621, 2005.

García-Herrera, R., Hernández, E., Paredes, D., Barriopedro, D., Correoso, J. F., and Prieto, L.: A MASCOTTE-based characterization of MCSs over Spain, 2000-2002, Atmos. Res., 73, 261$282,2005$.

García-Herrera, R., Barriopedro, D., Hernández D., Paredes, D., Correoso, J. F., and Prieto, L.: The 2001 Mesoscale Convective Systems over Iberia and Balearic Islands, Meteorol. Atmos. Phys., 90, 225-243, 2005.

Hoskins, B. J., Draghici, I., and Davies, H. C.: A new look at the $\omega$ equation, Quart. J. R. Meteorol. Soc., 104, 31-38, 1978.

Hoskins, B. J., McIntyre, M. E., and Robertson, A. W.: On the use and significance of isentropic potential vorticity maps, Quart. J. R. Meteorol. Soc., 111, 877-946, 1985.

James, P., Stohl, A., Spichtinger, N., Eckhardt, S., and Foster, C.: Climatological aspects of the extreme European rainfall of $\mathrm{Au}-$ gust 2002 and a trajectory method for estimating the associated evaporative source regions. Nat. Hazards Earth Syst. Sci., 4, 733746, 2004,

http://www.nat-hazards-earth-syst-sci.net/4/733/2004/.
Lamarque, J. F. and Hess, P. G.: Cross-Tropopause Mass Exchange and Potential Vorticity Budget in a Simulated Tropopause Folding, J. Atmos. Sci., 51(15), 2246-2269, 1994.

Nieto, R., Gimeno, L., de la Torre, L., Ribera, P., Gallego, D., García-Herrera, R., García, J. A., Núñez, M., Redaño A., and Lorente, J.: Climatological features of Cut-off Low Systems in the Northern Hemisphere, J. Climate, 18, 3085-3103, 2005.

Paredes, D., Trigo, R. M., Garcia-Herrera, R., and Franco, I.: Understanding Precipitation Changes in Iberia in Early Spring: Weather Typing and Store-Tracking Approaches, J. Hydrometeorol., 7, 101-113, 2006.

Romero, R., Doswell, C. A., and Ramis, C.: Mesoscale Numerical Study of Two Cases of Long-Lived Quasi-Stationary Convective Systems over Eastern Spain, Mon. Weather Rev., 128, 3731-3750, 2000.

Sprenger, M., Wernli, H., and Bourqui, M.: StratosphereTroposphere Exchange and its Relation to Potential Vorticity Streamers and Cutoffs near the Extratropical Tropopause, J. Atmos. Res., 64, 1587-1602, 2007.

Stohl A. and James, P.: A Lagrangian Analysis of the Atmospheric Branch of the Global Water Cycle, Part I: Method Description, Validation, and Demonstration for the August 2002 Flooding in Central Europe, J. Hydrometeorol., 5(4), 656-678, 2004.

Stohl A. and James, P.: A Lagrangian Analysis of the Atmospheric Branch of the Global Water Cycle, Part II: Moisture Transports between Earth's Ocean Basins and River Catchments, J. Hydrometeorol., 6(6), 961-984, 2005.

Trigo, R. M. and DaCamara, C.: Circulation Weather Types and their Influence on the Precipitation Regime in Portugal, Int. J. Climatol., 20, 1559-1581, 2000. 